\title{
ESCRITA E PODER EM CAROLINA MARIA DE JESUS: A TRADUÇÃO DE TEXTOS AFRO-BRASILEIROS
}

\begin{abstract}
Marcela Iochem Valente é professora adjunta de língua inglesa da Universidade do Estado do Rio de Janeiro, doutora em Estudos da Linguagem pela PUC-Rio e mestre em Literaturas de Língua Inglesa pela UERJ. Atua na área de Estudos da Tradução com ênfase em questões de tradução das literaturas afro-americana e afro-brasileira.

E-mail: marcellaiv@ig.com.br
\end{abstract}

Renata Thiago Pontes é doutoranda do Doutorado em Literatura Comparada da Universidade do Estado do Rio de Janeiro e mestre em Letras pelo Mestrado em Literaturas de Língua Inglesa da mesma instituição. Atua na área de Estudos da Tradução com ênfase em tradução intercultural nas literaturas de língua inglesa e na literatura brasileira.

E-mail: rethipon@gmail.com.br

Resumo: O presente artigo objetiva discutir questões referentes à tradução de textos afrobrasileiros para a língua inglesa. Veremos que a tradução de obras de escritores como Carolina Maria de Jesus pode (des)construir imagens culturais, questionando a História oficial que tende a excluir os grupos pertencentes à margem de nossa sociedade e revendo questões como o mito da democracia racial. $\mathrm{O}$ arcabouço teórico será constituído por Even-Zohar, Lefevere e Barker.

\begin{abstract}
This article aims at discussing questions related to the translation of AfroBrazilian texts into English. It shows that the translation of texts such as Carolina Maria de Jesus' can (de)construct cultural images, questioning official History which tends to exclude marginal groups and reviewing questions as the myth of racial democracy. The theoretical background to this research includes some ideas of Even-Zohar, Lefevere and Barker.
\end{abstract}

\section{1) Introdução}

O objetivo deste estudo é discutir algumas questões relacionadas à tradução da literatura afro-brasileira para a língua inglesa e a sua recepção no contexto estadunidense. Assim como a literatura pode funcionar como uma forma de dar voz a grupos historicamente excluídos, a tradução da produção literária desses grupos pode ser uma maneira de amplificar essas vozes, fazendo com que os questionamentos e protestos abordados em tais obras possam ser lidos e ouvidos em maior escala.

Quando tratamos de obras provenientes de contextos não hegemônicos, como a literatura brasileira, traduzidas para polissistemas que detém certa hegemonia, como o estadunidense, essas vozes encontram ainda mais possibilidades de serem ouvidas. Através do estudo de questões relacionadas à tradução da obra Quarto de despejo, da escritora afro-brasileira Carolina Maria de Jesus para o inglês, este artigo visa articular questões como a relação entre escrita, poder e tradução. A tradução de obras como a de Carolina Maria de Jesus pode mudar a imagem cultural que outros países têm do Brasil, questionando e desconstruindo relatos oficiais como o mito da democracia racial e trazendo à luz histórias por muito tempo apagadas e/ou esquecidas.

A presente pesquisa tem como pressupostos teóricos a teoria dos polissistemas, tal qual proposta por Itamar Even-Zohar (1990, 1997); os estudos descritivos da tradução, considerando algumas ideias de André Lefereve (1981, 1990, 2007); e os estudos culturais segundo os pressupostos estabelecidos por Chris Barker (2008).

Essa pesquisa visa contribuir para os estudos de literatura afro-brasileira e para os estudos da tradução, pois pouquíssimos são os estudos sobre a tradução de obras provenientes do sistema de literatura afro-brasileira e escassas são as referências sobre a tradução da obra de Carolina Maria de Jesus. Nossa opção pela obra de Carolina para 
esse estudo se dá devido ao fato de que ela foi a primeira escritora afro-brasileira a ter sua obra traduzida para o inglês e ainda para diversos outros idiomas, como veremos neste artigo.

\section{2) Pressupostos Teóricos}

A teoria dos polissistemas foi desenvolvida pelo israelense Itamar Even-Zohar no final da década de 1970 com o objetivo inicial de explicar particularidades da história da literatura hebraica e das traduções literárias existentes nessa cultura. Essa teoria concebe uma cultura como um sistema internamente constituído por outros sistemas que se interrelacionam, sendo, por essa razão, chamado de polissistema (EVEN-ZOHAR, 1990). Os sistemas, por sua vez, são redes dinâmicas e hierarquizadas cujas fronteiras estão constantemente se redefinindo. Assim, um polissistema na teoria de Even-Zohar referese a um agregado de sistemas existentes em uma dada cultura, sendo alguns centrais e outros periféricos. Porém, esses sistemas não são estáticos, pois há uma tensão constante na relação de poder existente entre os elementos dos sistemas, já que os elementos centrais (canônicos) se esforçam por manter sua posição, enquanto os periféricos (não canônicos) buscam alcançar essa centralidade. Em "Beyond the Process: Literary Translation in Literature and Literary Theory" (1981), André Lefevere observa que o termo polissistema denota que uma literatura não se configura como um conjunto monolítico de obras, e sim como uma combinação de tendências diferentes, frequentemente antagônicas, entre as quais predomina o conjunto de obras literárias que pertencem ao cânone de cada época, isso é, aquelas que estão ocupando a posição central no sistema em dado momento (LEFEVERE, 1981, p. 55). Porém, o autor ressalta que o polissistema literário não é constituído apenas de obras consagradas pertencentes ao cânone, mas também daquelas que tradicionalmente são deixadas à margem, como as traduções e as obras produzidas por grupos historicamente excluídos, como os afrodescendentes, por exemplo.

A teoria dos polissistemas é instrumental a esta pesquisa na medida em que tomamos como pressuposto a visão da literatura como um polissistema e buscamos compreender a importância da tradução de obras de contextos não hegemônicos, investigando questões relacionadas à tradução e a recepção de Quarto de despejo, da escritora afro-brasileira Carolina Maria de Jesus.

As ideias de Even-Zohar em relação à literatura como um polissistema foram expandidas por estudiosos como Gideon Toury e André Lefevere. Lefevere adota como pressuposto a teoria dos polissistemas, porém imprime-lhe uma orientação diferente daquela proposta por Even-Zohar e Toury através da incorporação de fatores extrínsecos, explicitando a dimensão da chamada patronagem, ou estruturas de poder, além da relação de interdependência e influência recíproca entre as traduções e as culturas receptoras.

Em Tradução, reescrita e manipulação da fama literária (2007) André Lefevere defende que a tradução é um tipo de reescrita e, como tal, é potencialmente "influente por sua capacidade de projetar a imagem de um autor e/ou uma obra (série de) obra(s) em outra cultura, elevando o autor e/ou as obras para além dos limites de sua cultura de 
origem" (LEFEVERE, 2007, p. 24). Diante disso, muitas vezes a tradução constrói novas imagens para os autores e/ou obras traduzidas e transforma o texto-fonte a fim de atender a certos interesses da cultura de chegada. Assim, Lefevere defende que "a tradução cria uma imagem do texto original, de seu autor, de sua literatura e de sua cultura" (LEFEVERE, 1990, p. 14-15).

$\mathrm{O}$ estudioso ilustra o seu argumento de que a tradução pode criar diferentes imagens para um autor/obra, apontando que muitos clássicos feministas publicados nos anos 1920, 1930 e 1940, aparentemente "esquecidos", foram republicados nos anos 1970 e 1980 sobre o pano de fundo de um conjunto de ideias feministas. Embora o valor intrínseco de tais obras não tenha mudado, o pano de fundo desse período as incorpora e fundamenta, podendo propor uma nova leitura para as mesmas e criar uma outra imagem para essas obras e suas autoras (LEFEVERE, 2007, p. 14). Partindo desse princípio, é interessante notar o ostracismo em que esteve Carolina Maria de Jesus no Brasil durante muitos anos embora, nesse mesmo período, sua obra estivesse sendo traduzida para outras línguas e lida em outros polissistemas, cujos panos de fundo a incorporava. Ainda hoje, no Brasil, a obra de Carolina não é muito conhecida e nem estudada fora do contexto das literaturas afrodescendentes.

Assim, os estudos descritivos da tradução (DTS), tal qual propostos por Lefevere, são instrumentais para essa pesquisa por se ocuparem de questões como o papel e a influência que as traduções exercem na literatura e cultura receptora, e a imagem que a cultura receptora forma em relação às obras traduzidas e seus autores.

Por fim, algumas ideias provenientes dos estudos culturais também orientarão o presente trabalho, mais especificamente aquelas que dizem respeito aos estudos de gênero e sobre a crítica pós-colonial. Segundo Chris Barker, em seu livro Cultural Studies Theory and Practice (2008), os Estudos Culturais estão centrados nas questões dos significados culturais, ou seja, as várias formas através das quais percebemos o mundo, especialmente através da linguagem; nas representações, práticas, línguas e costumes de uma sociedade específica. Os Estudos Culturais também refletem sobre como o mundo é socialmente construído e representado para e por nós, como os significados são produzidos em diversos contextos (BARKER, 2008, p. 7-8).

No sentido de investigar como o mundo é socialmente construído e tentando estabelecer uma forma de compreender a relação entre poder e consentimento, o conceito de hegemonia foi repetidas vezes explorado nas primeiras pesquisas da área dos Estudos Culturais. O conceito de hegemonia compreende uma situação em que um 'bloco histórico' de grupos poderosos exerce autoridade social e liderança sobre outros grupos subordinados (BARKER, 2008, p. 10-11). Esses grupos subordinados variam de acordo com o contexto colonizado: subordinados por colonizadores, grupos de menor poder aquisitivo por grupos de maior poder aquisitivo, mulheres por homens (em sociedades patriarcais), e outros.

Seguindo esse fluxo de pensamento que dá destaque aos grupos considerados subordinados, com o desenvolvimento do pensamento feminista, o papel da prática acadêmica patriarcal passou a ser constantemente questionado. Nesse sentido, a crítica feminista buscou promover debates e reflexões acerca do espaço relegado à mulher na 
sociedade patriarcal, questionando a posição de mulher-objeto, submissa, subjugada e sem voz.

Nomes como Kate Millet, Elaine Showalter, Hélène Cixous, Julia Kristeva e Gayatri Spivak, apenas para citar alguns, são fundamentais para o desenvolvimento das ideias feministas, porque cada uma dessas pesquisadoras, embora seguindo linhas distintas e partindo de pressupostos diferentes, contribuíram para esse novo olhar proposto em relação à mulher e ao seu espaço na sociedade. Todo esse movimento, além de questionar valores hegemônicos e dar voz a mulheres antes silenciadas, também promoveu uma rediscussão dos cânones literários que acabou evidenciando, de certa forma, o alcance de textos e seres traduzidos.

Sherry Simon (1996) afirma que era apenas uma questão de tempo até que os Estudos Culturais "descobrissem" a tradução, pois desde a globalização dos meios de cultura vivemos em mundos traduzidos. A língua, assim como a posição dos falantes dentro dos códigos dominantes, adquiriu um importante papel nesse panorama. As línguas são entendidas como peças centrais nos processos através dos quais as identidades individuais e coletivas são construídas.

A tradução é mais frequentemente utilizada pelos teóricos dos estudos culturais como uma metáfora, uma figura retórica, que por um lado descreve a crescente internacionalização da produção cultural e por outro o destino daqueles que lutam para viver entre dois mundos e duas culturas. A tradução passou a simbolizar, nesse contexto, a dificuldade de acesso à língua, de uma exclusão dos códigos daqueles que estão no poder. Para aqueles que se sentem marginalizados pelos códigos autoritários da cultura ocidental, a tradução representa uma metáfora para sua experiência ambígua na cultura dominante. Os imigrantes começam a definir a si mesmos como seres traduzidos.

Assim como os estudos da tradução apresentam contribuições para os estudos culturais, o oposto também acontece. Os estudos culturais trazem para os estudos da tradução um entendimento sobre as complexidades de gênero e cultura e enfatizam a multiplicidade das línguas que circulam no mundo hoje, a competição entre o global e o local, e a reatualização do formato das culturas (SIMON, 1996, p. 134-136). Em se tratando da tradução de obras de grupos historicamente excluídos, a interface entre os estudos culturais e os estudos da tradução se faz extremante relevante. Assim, podemos dizer que com o avanço das pesquisas em ambas as áreas, muitos pontos de interseção e colaboração foram surgindo e hoje essas áreas podem ser vistas como, de certa maneira, complementares.

Quando atentamos para a representação de grupos historicamente excluídos na literatura, observamos que, na literatura brasileira, por exemplo, desde sua formação até a contemporaneidade, os sujeitos afrodescendentes têm sido, muitas vezes, apresentados a partir de discursos hegemônicos. É notável que em diversas obras, a mulher negra é apresentada como um simples corpo-objeto relacionado a um passado de escravidão e, os afrodescendentes, de um modo geral, ao invés de possuir voz, são falados. Entretanto, esse discurso literário estereotipado negativamente pode ser questionado e subvertido pela produção literária de autoras negras que deixam, então, de ser objeto da representação de um outro para ocuparem a posição de sujeito e objeto da escrita 
literária. Através de suas perspectivas marcadas pela vivência de mulher, negra e algumas vezes ainda de classe social desfavorecida, essas escritoras contribuem para a constituição de uma história que revela elementos apagados, desprivilegiados e/ou manipulados pela escrita hegemônica. Assim, a obra literária produzida por escritoras afrodescendentes, como Carolina Maria de Jesus, pode ser vista como uma forma de dar voz a esse "outro", descortinando partes de nossa história que muitas vezes são manipuladas a partir de relatos e interesses hegemônicos. De maneira semelhante, a tradução de tais obras e a sua recepção em outros polissistemas literários também pode ter um caráter subversivo, indo na direção oposta às representações estereotipadas e, portanto, demandando traduções conscientes de toda a complexidade do polissistema de partida, incluindo as questões históricas, políticas, ideológicas, entre outras que permeiam a literatura afro-brasileira.

\section{3) Alguns desafios da literatura afro-brasileira}

Para melhor compreendermos questões relacionadas à recepção da literatura afrobrasileira, quer seja no contexto em que é produzida quer seja no contexto de recepção de suas traduções, é necessário trazermos algumas considerações sobre esse sistema literário, já que esse é um sistema ainda não consagrado e não consolidado no polissistema literário brasileiro. Assim, antes de falarmos especificamente de Carolina Maria de Jesus e de sua obra, teceremos alguns comentários sobre o sistema literário em questão.

A literatura afro-brasileira ainda é um sistema em busca de seu espaço no nosso polissistema literário. O fato de o negro aparecer como tema em obras literárias ou de podermos citar obras produzidas por negros há séculos não significa que a literatura afro-brasileira já seja uma discussão de longa data no Brasil. Nas obras de escritores canônicos, o negro geralmente aparece de forma estereotipada, tido como ingênuo, submisso, inferior ou ainda como objeto erótico, no caso da figura da mulata.

Diferentemente de sistemas como a literatura afro-americana, por exemplo, sistema há décadas reconhecido, consolidado e bem delineado, o sistema de literatura afro-brasileira não apenas está em busca de seu reconhecimento e consolidação, mas ainda é alvo de muitos questionamentos e críticas, algumas que até acreditam ser irrelevante se estudar um sistema como esse. Isso porque esse tipo de literatura desconstrói a ideia de uma identidade nacional una e coesa, sem conflitos de gênero, classe, raça e/ou etnia. Como observa Araújo,

no caso da literatura brasileira, entendemos que os contornos teóricos da literatura afrodescendente passam, em primeiro lugar, pela desconstrução do conceito de uma identidade nacional una e coesa que, por sua vez, descansa sob o manto da harmonia e homogeneidade geralmente ligadas a noções de nacionalidade. Argumenta-se, então, a partir deste critério, que nossa literatura é uma só - brasileira - e, assim, não teríamos a necessidade de demarcar territórios específicos - sejam eles étnicos, de classe ou gênero, fragmentando o corpo de nossa tradição literária (ARAÚJO, 2007, p. 18).

Se, por um lado, há questionamentos quanto à necessidade da criação de um sistema que abarque a literatura brasileira produzida por afrodescendentes, por outro 
lado, há um grupo de escritores e pesquisadores brasileiros que não apenas defendem o sistema de literatura afro-brasileira como já existente no polissistema literário brasileiro, mas também reúnem seus esforços para delinear as fronteiras desse sistema, para eles em fase de consolidação. A professora e pesquisadora Florentina da Silva Souza, por exemplo, em seu livro Afro-descendências em Cadernos Negros e jornal do MNU (2005), já em uma tentativa de delinear o que seria a literatura afro-brasileira, aponta que

[n]ão será a cor da pele ou a origem étnica o elemento definidor dessa produção textual, mas sim o compromisso de criar um discurso que manifeste as marcas das experiências históricas e cotidianas dos afro-descendentes no país. O conjunto de textos circula pela história do Brasil, pela tradição popular de origem africana, faz incursões no iorubá e na linguagem dos rituais religiosos, legitimando tradições, histórias e modos de dizer, em geral ignorados pela tradição instituída (SOUZA, 2005, p. 61).

Com posicionamento semelhante ao de Souza, já considerando o sistema de literatura afro-brasileira como existente no polissistema literário brasileiro, a escritora Conceição Evaristo, em entrevista a Eduardo de Assis Duarte publicada no quarto volume da antologia Literatura e afrodescendência no Brasil: antologia crítica (2011), inclusive se define como escritora pertencente a tal sistema.

Eu sou uma escritora brasileira, mas não somente. A minha condição de brasileira agrega outras identidades que me diferenciam: a de mulher, a de negra, a de oriunda das classes populares e outras ainda, condições que marcam, que orientam a minha escrita, consciente ou inconsciente. Nesse sentido, não tenho receio algum em não só afirmar a existência de uma literatura afro-brasileira, como ainda me encaixar no grupo de autoras/es que criam um texto afro-brasileiro. E ainda asseguro a existência de um texto feminino negro, ou afro-brasileiro, como queiram. $\mathrm{O}$ meu texto se apresenta sob a perspectiva, sob o ponto de vista de uma mulher negra inserida na sociedade brasileira (DUARTE, 2011, p. 114).

Em Brasil Afro Autorrevelado (2010), Miriam Alves - uma das reconhecidas escritoras afro-brasileiras contemporâneas - traça uma espécie de panorama da literatura afro-brasileira e aponta que esta

[p]ode até ser um conceito em construção academicista, mas consiste numa prática existencial para os seus produtores, que ressignifica a palavra negro, retirando-a de sua conotação negativa, construída desde os tempos coloniais, e que permanece até hoje, para fazê-la significar autorreconhecimento da própria identidade e pertencimento etnicorracial (ALVES, 2010, p. 42, grifo da autora).

Segundo Alves, a literatura afro-brasileira é, na verdade, "uma manifestação literário-cultural que foi adquirindo fortes feições de movimento literário" (ALVES, 2010, p. 7) e que busca valorizar a literatura produzida por afrodescendentes, inscrevendo tal grupo na história, valorizando as origens africanas, ressaltando a diversidade presente em nossas sociedades e possibilitando que esses sujeitos, por muito tempo silenciados ou "falados", falem por si mesmos.

Antes de concluirmos a presente seção, acreditamos ser importante esclarecer que a literatura afro-brasileira não abarca apenas escritos femininos, embora tenhamos escolhido trabalhar com a literatura de autoria feminina no presente artigo. Essa escolha 
se deu pelo fato de a produção de autoria feminina no sistema de literatura afrobrasileira possuir grande relevância e destaque, conseguindo algumas vezes, alcançar visibilidade até mesmo fora do Brasil, como é o caso da escritora contemporânea Conceição Evaristo e de Carolina Maria de Jesus, aqui estudada. A contribuição de tais produções para o movimento negro no Brasil também foi um fator relevante para essa escolha.

\section{4) Literatura (afro-)brasileira em tradução}

Ao falarmos sobre a literatura afro-brasileira traduzida para a língua inglesa e publicada no polissistema literário estadunidense, faz-se necessário tecer algumas breves considerações sobre a literatura brasileira traduzida para esse polissistema. Estudos sobre a literatura brasileira traduzida demonstram que nossa literatura e cultura ocupam uma posição periférica nos polissistemas de língua inglesa. Mesmo com o crescimento dos incentivos no Brasil para que nossa literatura seja levada para outras línguas e outros sistemas literários, o número de obras traduzidas ainda é bastante reduzido, e o estudo dessas traduções ainda mais raro.

Em sua dissertação de mestrado Identidades Refletidas: um estudo sobre a imagem da literatura brasileira construída por tradução (2005), Maria Lúcia Santos Daflon Gomes apresenta um levantamento de obras da literatura brasileira traduzidas para os polissistemas de língua inglesa ao longo do século XX. Partindo de outro levantamento apresentado anteriormente por Heloisa Barbosa, em 1994, e da pesquisa em fontes como o guia Babelguides de obras brasileiras em tradução para o inglês, Gomes aponta que

foi possível contar 166 obras de ficção, na maioria romances, traduzidas (ou retraduzidas) para o inglês ao longo de 94 anos, a partir do início do século XX até o ano de 1994, quando ela [Barbosa] encerrou [sua] pesquisa. Somando-se a esse número mais 19 obras traduzidas entre 1990 e 1994, não incluídas na pesquisa de Barbosa, e outras 21 traduzidas entre 1995 e 2000, a média do século XX chega a 2,08 livros por ano, com 100 autores traduzidos (GOMES, 2005, p. 59-60).

Ao falarmos da tradução da literatura brasileira para a língua inglesa, podemos citar alguns nomes de destaque, como os escritores canônicos Jorge Amado, considerado um dos escritores brasileiros mais traduzidos para o polissistema literário anglo-americano; os consagrados pela crítica literária Machado de Assis e Clarice Lispector; assim como o escritor contemporâneo Paulo Coelho que, embora não tenha alcançado grande sucesso com a crítica, está entre os escritores brasileiros mais traduzidos e mais vendidos no polissistema literário estadunidense, não se devendo esquecer de que nos Estados Unidos a literatura traduzida não é alvo de interesse prioritário dos leitores.

Gomes aponta em seu estudo que, até década de 1980, autores canônicos lideraram a classificação dos mais traduzidos, devido à importância da academia e da crítica universitária na seleção e na tradução de textos literários brasileiros. Muitas das traduções desse período foram publicadas por editoras ligadas a universidades (GOMES, 
2005, p. 64-66). Apenas a partir da década de 1990, a popularidade dos autores no polissistema de origem passou a ser também um critério importante na seleção de obras brasileiras para tradução. Assim, "o que antes se fazia majoritariamente a partir de referências acadêmicas, passou a ser feito de acordo com a lógica do mercado" (GOMES, 2005, p. 73), influenciando também a "feição do sistema de literatura brasileira traduzida para o inglês. $\mathrm{O}$ autor que vende bem aqui é forte candidato a se lançar em tradução" (GOMES, 2005, p. 91).

No artigo "A tradução da literatura brasileira" (2011), o antropólogo e jornalista Felipe Lindoso argumenta que, embora o português seja o terceiro idioma ocidental com mais falantes no mundo, "a projeção internacional da literatura produzida em português depende das traduções. E depende muitíssimo de traduções para o inglês, pois a partir desse idioma - a língua franca - é que se processa a difusão para os demais" (LINDOSO, 2011, s/n.). O surgimento de um interesse comercial pela literatura brasileira apontado por Gomes (2005) contribuiu para a geração de um canal de exportação de autores nacionais, o que é bastante positivo por dar maior visibilidade à nossa cultura e literatura.

Com o crescimento dos estudos culturais, os estudos feministas, homoeróticos, latinos e estudos relacionados a questões de gênero e etnia, de um modo mais amplo, vêm alcançando maior visibilidade. Com isso, o interesse acadêmico na produção cultural e literária de tais grupos e/ou comunidades também tem crescido, impulsionando o processo de tradução dessas produções. $\mathrm{O}$ processo de inserção dessas obras no polissistema literário estadunidense por via da tradução pode influenciar a imagem da literatura e da cultura brasileira nesse contexto, questionando e/ou desconstruindo estereótipos ou imagens criadas pelas traduções majoritariamente canônicas presentes em tal sistema até então. Gomes comenta que

[e]m alguns casos, a utilização de textos como material de estudo para essas áreas gerou rótulos rejeitados pelos autores, como no caso de Caio Fernando Abreu, tomado como escritor gay, ou recebidos com surpresa pela crítica e pela própria comunidade de leitores da cultura fonte, como no caso de Clarice Lispector, cuja ligação com o feminismo vem do exterior (GOMES, 2005, p. 75).

No caso da inserção da literatura afro-brasileira no polissistema literário estadunidense, podemos perceber claramente a desconstrução da imagem do Brasil como uma democracia racial. Porém, o número de traduções de obras provenientes do sistema de literatura afro-brasileira para o contexto estadunidense ainda é muito reduzido. Se, a literatura brasileira aqui reconhecida pela crítica e canonizada, ou reconhecida pelo público e sucesso de vendas, não possui muito espaço no sistema de literatura brasileira traduzida nos Estados Unidos, menos espaço ainda possui a literatura pertencente às margens de nosso polissistema literário.

Em Brazilian Women Writers in English: translation of culture and gender in works by Clarice Lispector, Carolina Maria de Jesus, and Ana Maria Machado (2008), tese de doutorado desenvolvida na Universidade de Massachusetts, Lilian Feitosa discute a inserção das escritoras brasileiras citadas no título de seu trabalho no polissistema literário estadunidense pela via da tradução. Além das escritoras canônicas 
Clarice Lispector e Ana Maria Machado, Feitosa inclui em sua pesquisa a primeira escritora afro-brasileira a ter sua obra traduzida para o inglês, Carolina Maria de Jesus. Porém, antes de abordar as traduções das três escritoras em questão, Feitosa apresenta um levantamento das traduções de obras provenientes do sistema de literatura brasileira para o inglês a partir do exame da história literária brasileira e de listas oficiais de autores brasileiros fornecidos pela Biblioteca Nacional e pelo Ministério da Cultura do Brasil, a fim de ter uma ideia do número de escritores (homens e mulheres) presentes nas histórias oficiais da literatura brasileira. Além do seu levantamento, Feitosa utiliza ainda três estudos antecessores da sua pesquisa: a tese de doutorado de Heloisa Gonçalves Barbosa (1994), a dissertação de mestrado de Maria Lúcia Santos Daflon Gomes (2005) - ambos já citados neste artigo - e a tese de doutorado de Carla Melibeu Bentes, intitulada Clifford Landers - tradutor do Brasil (2005). Feitosa aponta que "os resultados obtidos ao final da coleta de dados em 21 de março de 2007 apresentam um total de 12.931 autores: 10.618 homens (82\%) e 2.313 mulheres (18\%)" (p. 83), o que mostra um número consideravelmente pequeno de obras traduzidas e, menor ainda, de traduções de obras provenientes de grupos vistos como historicamente excluídos, como mulheres, afro-descendentes e, ainda, no caso do estudo de Feitosa, de literatura infantil. Para ressaltar sua constatação, Feitosa fornece um exemplo que claramente demostra o desequilíbrio comercial existente entre as indústrias editoriais britânicas e estadunidenses e suas contrapartes estrangeiras: o fato de que, de acordo com a UNESCO, em 1987, 1.500 traduções do inglês foram trazidas para o Brasil, enquanto que apenas quatorze obras da literatura brasileira foram levadas pelos editores britânicos e estadunidenses (FEITOSA, 2008, p. 24).

Não podemos deixar de mencionar que, certamente, fatores históricos muito contribuíram para essa presença reduzida da literatura produzida por grupos marginalizados em tradução. Durante a Ditadura do Estado Novo (1937-1945) e a Ditadura Militar (1964-1985) a expressão da criatividade e do pensamento crítico foram duramente reprimidos. Com isso, no intuito de evitar a formação de sujeitos pensantes que pudessem se opor ao sistema, só eram admitidas pela censura, leituras de textos comprometidos com o sistema ou que não trouxessem oposição e questionamentos. A produção literária também foi duramente controlada. Muitos escritores e artistas em geral precisaram buscar exílio em outros países para que pudessem continuar produzindo fora dos padrões estabelecidos pelo sistema, fugindo, assim, da repressão. Apenas após o período de repressão ditatorial mais intensa é que a literatura voltou a apresentar, de forma mais aberta, o seu status questionador e, só então, a produção dos grupos tidos como minorias começaram a ganhar mais força e a conseguir algum espaço. Certamente, isso também se reflete na tradução.

Cabe ressaltar ainda que a primeira obra publicada por uma escritora afrodescendente no Brasil e traduzida para o inglês, alcançando grande e inesperado sucesso, foi Quarto de despejo de Carolina Maria de Jesus, objeto de nosso estudo, em 1960. Segundo Feitosa, após um curto período de sucesso, Carolina e suas obras desapareceram da vista e do interesse do público (FEITOSA, 2008, p. 260). Certamente, o novo período de ditadura iniciado em 1964 muito contribuiu para o desaparecimento da obra de Carolina no Brasil. Quando Carolina Maria de Jesus morreu, em fevereiro de 
1977, ela estava pobre e esquecida, alguns poucos grandes jornais relataram a sua morte. Ainda hoje, no Brasil, fora do sistema de literatura afro-brasileira, até mesmo a sua posição como escritora é questionada. Como aponta Eduardo de Assis Duarte na entrevista concedida à Valente e publicada em sua tese de doutorado, "[b]asta perceber o absoluto ostracismo em que está Carolina de Jesus hoje, ela não faz parte de nenhum programa universitário, ela não é lida em canto algum, é apenas o fenômeno de uma catadeira de papel que publicou um diário nos anos 60 e ponto" (VALENTE, 2013, p. 141). É interessante notar que, embora Carolina esteja bastante esquecida no Brasil, sua obra foi traduzida para diversos idiomas e, até os dias de hoje, ainda é bastante estudada, principalmente com o foco em questões de gênero e etnia.

Nos Estados Unidos, por exemplo, encontramos estudos comparativos entre a sua obra e as obras de escritoras afro-americanas. Em uma rápida busca em livrarias virtuais, como a Amazon, é possível encontrar livros como The Life and Death of Carolina Maria de Jesus, do pesquisador estadunidense Robert Levine e do brasileiro José Carlos Meihy, publicado pela editora da Universidade do Novo México em 1995. Podemos afirmar seguramente que Carolina Maria de Jesus é uma escritora afrobrasileira lida, estudada e respeitada nos Estados Unidos por estudiosos interessados em literaturas da diáspora negra. Porém, é interessante notar, que pouquíssimos são os estudos sobre a tradução e a recepção das obras de Carolina.

Em sua tese de doutorado Escrevivências na diáspora: escritoras negras, produção editorial e suas escolhas afetivas - uma leitura de Carolina Maria de Jesus, Conceição Evaristo, Maya Angelou e Zora Neale Hurston (2011), Fernanda Felisberto Silva trata de uma questão fundamental no que diz respeito à publicação da literatura afro-brasileira. Um dos pontos de sua tese é a dificuldade encontrada por escritores afrobrasileiros no mercado editorial desse país. Silva nos lembra que já existe no Brasil um pequeno segmento editorial e de livrarias se estruturando em torno da temática étnicoracial negra (livrarias como a Kitabu, no Rio de Janeiro, e editoras como a Mazza, de Belo Horizonte, que publicou os dois romances da escritora Conceição Evaristo, e a Nandyala, também de Belo Horizonte, que publicou uma coletânea de contos e outra de poemas da mesma autora) porém, ainda assim, há grande dificuldade para publicar esse tipo de literatura (SILVA, 2011, p. 47). As editoras reconhecidas e com maiores estruturas ainda não abriram as portas para que esses grupos historicamente excluídos pudessem publicar as suas produções. Com isso, dadas as dificuldades para a publicação e a circulação de tal literatura no Brasil, a tradução de obras provenientes desse sistema literário ainda é bastante restrita.

\section{1) Carolina Maria de Jesus: algumas considerações sobre sua vida e obra}

Voltando então o nosso olhar para a escritora em questão, em março de 2014, Carolina Maria de Jesus completaria cem anos de vida. Muitas foram as comemorações em decorrência dessa data no meio literário, contudo, ainda assim, Carolina não é uma escritora muito conhecida pelo público brasileiro em geral.

Segundo Magnabosco e Ravetti, biógrafos de Carolina Maria de Jesus, ela nasceu em 14 de Março de 1914, em Sacramento, Minas Gerais, onde viveu sua infância e 
adolescência. Era filha de negros que, provavelmente, migraram do Desemboque para Sacramento quando houve a mudança da economia da extração de ouro para as atividades agropecuárias. Carolina foi mãe de três filhos: João José de Jesus, José Carlos de Jesus e Vera Eunice de Jesus Lima. Faleceu em 13 de Fevereiro de 1977, com 62 anos de idade e foi sepultada no Cemitério da Vila Cipó, cerca de $40 \mathrm{~km}$ do centro de São Paulo. Provavelmente foi matriculada em 1923, ainda em Sacramento, no Colégio Allan Kardec, fundado em 31 de Janeiro de 1907, por Eurípedes Barsanulfo. Nessa época, as crianças de baixa renda da cidade eram mantidas no Colégio através da ajuda de pessoas influentes. A benfeitora de Carolina Maria de Jesus foi a senhora Maria Leite Monteiro de Barros, pessoa para quem a mãe de Carolina trabalhava como lavadeira. No Colégio Allan Kardec Carolina estudou pouco mais de dois anos. Toda sua educação formal na leitura e escrita são frutos deste pouco tempo de estudos (MAGNABOSCO; RAVETTI, 2004, p. 1).

O jornalista Audálio Dantas é tido como quem "descobriu” Carolina de Jesus ao escrever uma matéria sobre a expansão da favela do Canindé em São Paulo que, em meados dos anos 1960, foi desocupada para que fosse construída a Marginal Tietê. Ao conversar com os moradores, o jornalista conheceu a escritora que lhe mostrou uma coleção de cerca de 20 cadernos, recolhidos do lixo, nos quais ela registrava o seu cotidiano. Dantas convenceu a editora Francisco Alves a publicar os diários de Carolina de Jesus sob o título Quarto de despejo, referência ao modo como a escritora percebia a favela em oposição à cidade, ou seja, o lugar onde é despejado o lixo da cidade. Nessa obra, através da linguagem simples e poética de Carolina Maria de Jesus, vemos retratado o cotidiano de uma mulher negra e de seus vizinhos para viver e sobreviver na favela e a luta para conseguir comida, remédios, roupas e para educar seus filhos. A narradora luta para não se adequar ao estereótipo da mulher negra e pobre e para conseguir condições melhores de vida. Ela encontra na educação e na escrita de seus diários a única saída para tentar subverter a situação de miséria e opressão em que vive (MEIHY; LEVINE, 1994, p. 173-174).

O livro tornou-se um sucesso editorial, sendo traduzido para treze línguas e mais de quarenta países, vendendo cerca de um milhão de cópias em todo o mundo. Os registros dos diários de Carolina de Jesus iniciaram-se em 15 de julho de 1955, sendo interrompidos em 28 de julho do mesmo ano e retomados apenas em 2 de maio de 1958. O último registro data de $1^{\circ}$ de janeiro de 1960. Mas nem o formato de diário nem a descontinuidade cronológica prejudicam a estrutura narrativa. Mesmo com dificuldades, a escritora ainda publicou, no Brasil, Casa de alvenaria (1961), Provérbios (1963) e Pedaços da fome (1963). Posteriormente a sua morte, em 13 de fevereiro de 1977, foram publicados Diário de Bitita (1982), Meu estranho diário (1996) e Antologia pessoal (1996). A obra de Carolina Maria de Jesus possui importância singular na literatura e na história brasileira, embora seja deixada à margem de nosso sistema literário segundo olhares hegemônicos e não seja (re)conhecida pelo público em geral.

Em Quarto de despejo vemos que a favela do Canindé enfrentava problemas graves como violência, fome, falta de condições básicas de higiene como água potável e saneamento básico e a falta de moradia para todos. As casas da favela, os barracos, eram feitos de papelão e pedaços de madeira. Carolina era catadora de papel. Vivia a revirar o 
lixo das casas dos bairros ricos e a revender o que encontrava para ganhar uns poucos trocados que usava para sustentar a si mesma e aos seus três filhos. Ela luta para manter seus filhos longe de más influências, mas a polícia começa a relatar problemas causados por seus filhos e uma vizinha acusa um deles, João, de estupro. Carolina acredita que a acusação seja falsa, mas passa a considerar internar seus filhos em um abrigo público para protegê-los. Contudo, dois fugitivos de um abrigo se hospedam na casa de Carolina e relatam abusos terríveis ocorridos nesses abrigos. Ela muda de ideia e passa a pensar que se seus filhos fossem para tais lugares, poderiam se tornar criminosos de fato.

Carolina menciona em seu livro os políticos Jânio Quadros, Adhemar de Barros e Carlos Lacerda. Ela critica as atitudes dos políticos que se aproveitam dos pobres, a exploração dos comerciantes e atacadistas e o desperdício de alimentos. Também faz muitas críticas ao sistema político que ela acredita contribuir para a pobreza e a fome dos favelados. Ela acredita viver em um sistema que conspira contra os pobres. Todas as vezes que sai da favela e vai para os bairros ricos da cidade de São Paulo, ela enfrenta preconceito racial e de classe social. Ela não busca casar-se e sim o bem estar de seus filhos.

Carolina se destaca como os olhos e ouvidos da favela. Um elemento de observação e denúncia. Em certos momentos, registra também suas reflexões interiores que, por vezes, são bastante poéticas e, outras vezes, críticas. Carolina valoriza, em sua obra, o poder da escrita como registro e como denúncia. Para ela a escrita, o letramento, significa poder, porque ela se defende de seus agressores com a escrita de seu livro, denuncia o que considera errado na vida da favela e na sociedade em que vive, vê na escrita a chave para sair da favela através da publicação do livro e da educação de seus filhos. Esses fatos podem ser confirmados em passagens como as que foram selecionadas abaixo: Elas diz:

Quando as mulheres feras invade o meu barraco, os meus filhos lhes joga pedras.

-Que crianças mal iducadas!

Eu digo:

-Os meus filhos estão defendendo-me. Vocês são incultas, não pode compreender. Vou escrever um livro referente a favela. Hei de citar tudo que aqui se passa. E tudo que vocês me fazem. Eu quero escrever o livro, e vocês com estas cenas desagradáveis me fornece os argumentos (JESUS, 2006, p. 17). ${ }^{1}$

O dia de hoje me foi benefico. As rascoas da favela estão vendo eu escrever e sabe que é contra elas. Resolveram me deixar em paz. Nas favelas os homens são mais tolerantes, mais delicados. As bagunceiras são as mulheres. As intrigas delas é igual a de Carlos Lacerda que irrita os nervos. E não há nervos que suporta. Mas eu sou forte! (JESUS, 2006, p. 18).

...Seu Gino veio dizer-me para ir ao quarto dele. Que eu estou lhe despresando. Disselhe: Não!

É que eu estou escrevendo um livro, para vendê-lo. Viso com esse dinheiro comprar um terreno para eu sair da favela. Não tenho tempo para ir a casa de ninguém, Seu Gino insistia (JESUS, 2006, p. 25).

\footnotetext{
${ }^{1}$ A primeira publicação de Quarto de despejo ocorreu em 1960 através da Editora Francisco Alves, mas foi utilizada neste trabalho a edição publicada em 2006 pela Editora Ática.
} 
A linguagem de Carolina é coloquial e apresenta desvios gramaticais e ortográficos decorrentes da pouca instrução formal da autora. Contudo, nenhuma dessas características desmerece nem desqualifica a obra que é mundialmente estudada, embora em contextos restritos, relacionados a questões raciais e sociais. A intervenção do jornalista Audálio Dantas ajuda Carolina de Jesus a publicar seus diários. Quando passagens deles aparecem na revista $O$ Cruzeiro (1959), Carolina conta a todos que encontra sobre sua fama. Por outro lado, a fama não traz os efeitos por ela esperados e ela continua a viver naquelas condições e passa a ter que lidar com comentários feitos na favela sobre o que ela escreveu. Carolina continuava sonhando em ter uma casa fora da favela.

A pesquisadora Germana Henriques Pereira de Sousa alega que a importância que Carolina dá aos meios de comunicação de massa, a mídia impressa, a televisão, ao rádio, tem a ver com o momento em que vive. É um momento no qual acontecia a difusão do saber de forma que atingisse as camadas mais pobres da população (SOUSA, 2012, p. 29).

Carolina percebe esse momento e quer fazer parte dele. Jogou várias vezes com a imprensa, dizia que a edição no Brasil ainda era incipiente, queria escrever para a revista Seleções do Rider's Digest. Carolina amava e odiava a mídia, vivia com ela uma relação conflituosa marcada pelo antes e pelo depois da fama, conforme descrito em Meu estranho diário (SOUSA, 2012, p. 29).

Elzira Divina Perpétua ressalta que a acolhida de Quarto de despejo no Brasil foi precedida pelo surgimento de uma nascente crônica urbana e do jornalismo investigativo, que denunciavam diferenças entre o progresso material do país e a pobreza da população. A concentração de riquezas fazia da capital paulista uma terra de contrastes. As reportagens ganhavam um sentido político, pois mostravam o dia-a-dia dos miseráveis e anônimos vindos de todas as partes e espalhados pela cidade. Essas matérias promoviam histórias que antes eram camufladas ou publicadas em jornais sensacionalistas e, sendo assim, eram logo esquecidas (PERPÉTUA, 2014, p. 51).

Germana Henriques Pereira de Sousa, em sua obra Carolina Maria de Jesus: o estranho diário de uma escritora vira-lata (2012), destaca que na segunda metade do século XX, no pós-guerra, houve uma intensificação no processo de modernização brasileiro, sobretudo com a proposta de avançar cinquenta anos em cinco. Porém a desigualdade social diminuiu bem menos do que o progresso tecnológico, e o sistema educacional, apesar de algumas melhorias, continuou fraco e, como até hoje, não acabou com o analfabetismo e nem propiciou às camadas mais populares o acesso aos bens culturais. Segundo Sousa, a literatura brasileira encontrou na modernização uma barreira: não serviu a ampliação de um público leitor porque esse público era empurrado pelo mercado em direção a sucata produzida pela indústria cultural dos países centrais (SOUSA, 2012, p. 27).

Contudo, a recepção da obra de Carolina Maria de Jesus vivenciou momentos diferentes no Brasil. Na época do lançamento de Quarto de despejo em 1960, a autora ficou relativamente famosa. Ganhou atenção da crítica e da mídia do Brasil e do 
exterior. O livro poderia causar um impacto político, mostrando ao Brasil e ao mundo a realidade da favela e da pobreza, mas, em 1964, houve o golpe militar. Segundo Joel Rufino dos Santos, "a ditadura, e a luta contra ela, afogou a recepção de Quarto de despejo" (SANTOS, 2009, p. 96). Carolina Maria de Jesus e sua obra começaram a sumir da mídia.

No Brasil, a cadeia de idealizações que toda sociedade respira, renovável a cada geração, se rompe nos anos 1960-1970. Carolina ajudou a romper o elo da democracia racial: o preto feliz e agradecido que não pede favores. A substituição dessas idealizações, que incluía a crença em um país ilimitadamente fecundo ... Coincidiu com um fenômeno mundial: a juvenilização da vida... Não se esperava que as mulheres dissessem algo diferente de "aproveitamos o sol, as ondas e a cama, a vida é bela e breve" (SANTOS, 2009, p. 103-104).

Meihy acredita que a crítica social contida em Quarto de despejo era inadequada às expectativas dos militares do golpe de 1964 e, dessa forma, Carolina passou a ter seu livro evitado pelos editores que o viam como perigoso e possivelmente censurado, o que, em termos econômicos, não seria bom para eles (MEIHY, 1994, p. 7-17). A carreira literária de Carolina Maria de Jesus coincidiu, em linhas gerais, com a ditadura militar: um período de ascensão e fama até 1965 e queda até 1977.

A esquerda que apresentou Carolina ao país, composta basicamente de estudantes, jornalistas, líderes sindicais e artistas, foi afastada de cena. Ocupada em se defender e, depois de 1969, lutar pela redemocratização e o socialismo, esqueceu a escritora do Canindé. Quando se lembrava dela era por seu conservadorismo político. Sua visão da favela era de dentro, a esquerda preferiu a de Sérgio Ricardo e Tom Jobim/ Vinícius que cantavam a felicidade do pobre e sua redenção futura. A literatura de Carolina seria de direita: preconceituosa, idealista, sem redenção. Não servia à ditadura, nem aos seus inimigos (SANTOS, 2009, p. 107).

\section{2) Carolina Maria de Jesus em tradução: Quarto de Despejo}

Nos Estados Unidos a acolhida de Carolina Maria de Jesus e sua obra foi completamente diferente do que encontramos no polissistema literário brasileiro. José Carlos Sebe Bom Meihy ressalta que para os países da Europa ocidental e especialmente para os Estados Unidos, a história de Carolina retratava um mundo injusto reforçado por séculos de colonialismo. Para os liberais estadunidenses, o diário de Carolina mostrava a corrupção do sistema. O livro também era lido avidamente em países do bloco socialista. No bloco oriental e em Cuba, o livro de Carolina parecia ilustrar as contradições do capitalismo e sua iminente exaustão. Meihy ressalta que a histórica dinâmica de cada um desses contextos literários: brasileiro, latino americano, europeu, estadunidense, capitalista, socialista, sugere que há muitas maneiras de ler as palavras de Carolina Maria de Jesus. Por que Carolina Maria de Jesus significava tantas coisas diferentes para inúmeros leitores? Como podemos abordar o trabalho dela hoje, sabendo o quanto as coisas mudaram desde que ela escreveu seu diário? Que fronteiras Carolina representava em seu tempo, para o Brasil, a América Latina, a Europa, o resto do mundo, os Estados Unidos? (LEVINE; MEIHY, 1995, p. 15-16). 
Meihy afirma que o fato de estar entre os negros do sul dos Estados Unidos depois da aprovação do Civil Rights Act em agosto de 1964 o marcou e permitiu que pudesse observar as diferenças entre as relações raciais nos dois países. Mais tarde ele assistiu com curiosidade quando os Panteras Negras destruíram o argumento de que os negros brasileiros e americanos agiam da mesma forma. Meihy declara se lembrar vividamente das referências feitas ao Brasil pelas pessoas que conheceu nos Estados Unidos: em geral eram sobre a floresta Amazônica, o samba, o futebol, e não muito mais que isso. Carmem Miranda encantou Hollywood e era a única pessoa brasileira que a maior parte das pessoas nos Estados Unidos conhecia. Ele relata que se irritava em ouvir que Buenos Aires era a capital do Brasil e também com a percepção de algumas pessoas, inclusive brasileiras, de que o Brasil não estava preparado para a democracia e que um governo militar era algo esperado. Muitas pessoas haviam ouvido falar em Carolina Maria de Jesus e associavam seu nome ao Brasil (LEVINE; MEIHY, 1995, p. 16-17).

Meihy afirma que os estadunidenses viam a obra de Carolina como literatura de protesto enquanto ele prestava mais atenção à animosidade entre Carolina e os nordestinos, a suas relações amorosas, sempre com homens brancos, e a forma como ela via o mundo. Meihy afirma que Carolina nunca participou de ações comunitárias para melhorar a vida da favela. Ela escrevia para escapar. Carlos Meihy declara que como ser negro muitas vezes significa ser miserável no Brasil, antes de protestar contra a pobreza as pessoas precisam considerar a questão da cor da pele também. Afinal, segundo ele, Carolina, escrevendo para os negros, representa a tradicional defensiva da literatura negra brasileira. Ela não abordava a questão da identidade racial. Em vez disso, ela buscava viver em paz em um mundo "melhor", o mundo dos brancos. Considerar o trabalho de Carolina como escrita negra levantou questões sobre os limites da aceitação social dos negros no Brasil. Se, para Meihy, os negros que conseguiram ascender socialmente no Brasil o fizeram através da música ou do futebol, Carolina seguiu um caminho diferente daquele traçado por Pelé e outros. Seu caminho era o literário. Meihy achava importante que seus alunos aprendessem que Carolina, após se tornar uma celebridade nacional, acabou sendo esquecida a medida que o mundo que ela descreveu mudou intensamente (LEVINE; MEIHY, 1995, p. 18- 19).

A frequência com que Quarto de despejo aparecia nas listas de leituras obrigatórias dos cursos sobre o Brasil nos Estados Unidos era espantosa. Meihy relata ter ouvido razões diferentes para este fato, mas a mais frequente foi a de que esse livro era um dos poucos disponíveis sobre nossa "realidade urbana", narrado por alguém que é parte dessa realidade, de dentro do domínio da miséria representado pela vida na favela. Com exceção de Jorge Amado, algumas obras de Machado de Assis, e mais recentemente de Clarice Lispector, quase não havia obras brasileiras em língua inglesa que pudessem ser adotadas por alguém que estivesse montando o programa de uma disciplina sobre o Brasil (LEVINE; MEIHY, 1995, p. 19).

Hoje, a obra de Carolina Maria de Jesus, que ainda goza de destaque no meio acadêmico de países como os Estados Unidos, volta a trilhar seu retorno à Academia brasileira. Contudo, esse retorno ainda está em curso, pois o número de pesquisas sobre ela ainda é relativamente pequeno se comparado com o número de pesquisas sobre 
obras canônicas da literatura brasileira, e o público leigo, em sua grande maioria, desconhece a autora. O caso de Carolina Maria de Jesus revela como a recepção de uma obra pode ser influenciada pelo contexto histórico e ideológico de uma sociedade e a importância da tradução para a divulgação e, até mesmo, a sobrevivência de uma obra literária. Enquanto a obra de Carolina Maria de Jesus foi ficando cada vez mais esquecida no Brasil, como já foi mencionado, no exterior ela continuou e continua a ser publicada e lida, e hoje, em Universidades da Ivy League estadunidense, como Dartmouth, faz parte do currículo dos cursos de literatura afrodescendente e de literatura brasileira.

Por outro lado, a literatura afrodescendente continua enfrentando muitos obstáculos como a dificuldade na tradução de suas obras para outras línguas, a aceitação de obras escritas por autores negros desconhecidos pelas editoras e a dificuldade no reconhecimento desses escritores como escritores de verdade. No Brasil, a maior parte da população não conhece os escritores afro-brasileiros e não tem ideia de que escritores canônicos e famosos, como Machado de Assis, são negros e não brancos. Por vezes, quando ensinam literatura brasileira a adolescentes, os professores não informam seus alunos das implicações culturais da negritude em trabalhos escritos por autores como Machado de Assis. Além disso, escritores como Carolina Maria de Jesus, que obtiveram uma larga aceitação pelo mercado internacional e tiveram seus livros traduzidos para muitas línguas, parecem ter sido condenadas ao esquecimento no cenário brasileiro, visto que, mesmo para os acadêmicos, fora do sistema de literatura afro-brasileira, a maior parte desses escritores são desconhecidos ou considerados escritores de segunda classe.

Dawn Duke (2008) ressalta que no Brasil as obras literárias de autoria negra são ainda extremamente ignoradas, com exceção de um número de leitores limitado formados por militantes dos movimentos negros ou especialistas da área. Em sua pesquisa por obras da autora afro-brasileira contemporânea Esmeralda Ribeiro em livrarias do Brasil, mais especificamente em São Paulo, Duke observou que elas não estão à venda em parte alguma e afirma que esse fato acentua ainda mais as dificuldades que uma escritora como Ribeiro, cujo tema central de suas obras é o racismo, sofre. A literatura de escritores como ela, que buscam mostrar uma perspectiva diferente da realidade vivida pelo negro no Brasil a partir de sua vivência, é produzida de forma independente e externa às grandes editoras brasileiras, como já apontamos. Duke acredita que esse aparente desinteresse pela literatura de Ribeiro, assim como de outras escritoras afro-brasileiras, é uma forma de discriminação institucional, segundo ela, um silenciamento, visto que suas obras inevitavelmente abordam questões importantes para suas vidas (DUKE, 2008, p. 1).

Através de um esforço conjunto e do desejo de publicar e serem lidos, alguns escritores se uniram e criaram a Quilombohoje, em 1978, da qual surgiu a famosa série Cadernos Negros. Todos os anos uma publicação de prosa ou poesia é feita com trabalhos de autores de todo o Brasil. Entre as escritoras publicadas pela série estão Esmeralda Ribeiro, Sônia Fátima da Conceição, Lia Vieira e Miriam Alves, que hoje são consideradas algumas das principais escritoras da década de 1970, uma geração de afirmação e luta através da escrita e da militância. Hoje, muitas dessas escritoras que 
começaram a escrever e publicar suas obras nos Cadernos Negros possuem suas próprias publicações independentes e são referência para todos os pesquisadores do sistema de literatura afro-brasileira. Contudo, enquanto as oportunidades de publicação continuarem a depender de esforços conjuntos das escritoras e tais publicações sobreviverem sem apoio financeiro e conexões com as grandes editoras, um imenso corpus literário continuará restrito a um público limitado, definido por seus interesses políticos e acadêmicos e outros fatores como status social e cor da pele (DUKE, 2008, p. 3).

De acordo com Niyi Afolabi (2001), através da mistura de conformismo social e resistência, a mulher afro-brasileira carrega um fardo multifacetado. Frequentemente desempenhando os papéis de mãe, amante, provedora, porta-voz, encorajadora, ela se torna fragmentada em um esforço de afirmar sua individualidade em meio às convenções sociais e os estereótipos raciais. Para quebrar esses papéis estereotipados, as mulheres afro-brasileiras precisam não apenas quebrar as convenções sociais, mas também compor seus papéis de forma mais profunda se tornando militantes e subversivas, em vez de subordinadas. Desde a época da escravidão, as mulheres afrobrasileiras são retratadas como escravas, servas domésticas, ou "mulatas", objetos sexuais cuja função é satisfazer os prazeres perversos de seus mestres, sem hesitação. Em contraste a essas imagens, as mulheres afro-brasileiras contemporâneas articulam, através da palavra escrita, suas vozes silenciadas e marginalizadas, exigindo respeito e dignidade assim como liberdade para serem quem são, sem restrições. O dilema coletivo da Quilomboje de ser reconhecido por editoras em geral e universitárias se apresenta como uma constante familiar no caso das mulheres, que são ainda mais marginalizadas que os homens. Ser mulher e negra no Brasil significa ser duplamente invisível (AFOLABI, 2001, p. 1-2). A publicação e a tradução de suas obras funcionam como uma forma de subverter essa invisibilidade a elas relegada.

\section{5) Considerações finais}

É interessante notar como a obra de Carolina Maria de Jesus foi recebida de maneiras completamente diferentes no Brasil e no exterior. Enquanto, em países como os Estados Unidos, Quarto de Despejo recebeu e recebe grande atenção, além de ser lido e estudado por muitos interessados em questões sociais e raciais, no Brasil, seu diário, assim como sua produção em geral, tiveram um curtíssimo período de glória, logo sufocado pelo momento histórico que estávamos vivendo, por trazer questionamentos que visavam subverter valores hegemônicos.

Levine, em seu artigo The cautionary tale of Carolina Maria de Jesus (1992), é incisivo ao afirmar que ao desmerecer as conquistas de Carolina e ressaltar as falhas em sua escrita, os jornalistas e críticos literários brasileiros na verdade estavam neutralizando o impacto que a obra dela deveria ter tido se tivesse sido lida por seu conteúdo. Levine destaca que, acima de tudo, Quarto de despejo e as outras obras de Carolina desconstruíam o mito da democracia racial no Brasil, um mito tão impregnado na cultura nacional que se alguém o desafiasse, especialmente uma mulher negra e favelada, esse alguém não deveria ser tolerado. Visivelmente, todas as críticas e 
comentários publicados evitavam as questões sobre as quais Carolina escreveu: a pobreza, a fome e o destino dos negros e das mulheres pobres. Os críticos se concentravam na figura de Carolina, transformando-a em uma curiosidade, ou pior, em uma mulher ranzinza e inconveniente. Era como se os acadêmicos, jornalistas, escritores e políticos brasileiros cerrassem fileiras para sufocar suas ponderações acerca da falta de democracia racial e o desprezo em relação às classes mais baixas, especialmente porque eram formadas por mulheres e homens negros (LEVINE, 1992, p. 21).

Também é bastante curioso o fato de sua obra ter sido traduzida para diversas línguas e ser estudada no exterior até os dias de hoje enquanto, aqui no Brasil, seu contexto de origem, a escritora e sua obra não são sequer conhecidas fora do contexto das literaturas afrodescendentes, do movimento negro e da academia. Podemos inferir que a tradução concedeu à obra de Carolina sua sobrevivência, pois ao sobreviver num polissistema literário diferente daquele em que foi criada, a obra garantiu também a possibilidade de retornar ao seu polissistema de origem. A escrita, o letramento e a tradução tiraram Carolina Maria de Jesus da favela, a levaram para o mundo, asseguraram sua sobrevivência, a colocaram nas universidades do mundo e a estão trazendo de volta para a Academia no Brasil.

Por fim, gostaríamos de ressaltar o fato de que a literatura afro-brasileira vem conseguindo pouco a pouco alcançar maior visibilidade através de escritoras como Carolina Maria de Jesus, Conceição Evaristo, Miriam Alves, entre outras, e das traduções de suas obras, embora esse sistema literário ainda esteja distante de ocupar um lugar central no polissistema de literatura brasileira.

\section{Referências}

AFOLABI, N. Beyond the curtains: unveiling Afro-Brazilian women writers. In: Research in African Literatures 32.4. Indiana: Indiana University Press, 2001. p. 117135.

ALVES, M. BrasilAfro Autorrevelado. Belo Horizonte: Nandyala, 2010.

ARAÚJO, F. S. Uma escrita em dupla face: a mulher negra em Ponciá Vicêncio, de Conceição Evaristo. 115p. Dissertação (Mestrado em Literatura e Cultura) - Programa de Pós-Graduação em Letras, Universidade Federal da Paraíba, 2007.

BARKER, C. Cultural Studies Theory and Practice. $3^{\text {rd }}$. Edition. London: Sage Publications, 2008.

DAVIES, C. B. Black, Women Writing and Identity: Migrations of the subjectivity. New York : Routledge, 1994.

DUARTE, E. A. (Org.). Literatura e afrodescendência no Brasil: antologia crítica. Belo Horizonte: Editora UFMG, 2011. Vol. 2 (a).

(Org.). Literatura e afrodescendência no Brasil: antologia crítica. Belo Horizonte: Editora UFMG, 2011. Vol. 4 (b). 
DUKE, D. Hidden sensations of strength in Afro-Brazilian Writings: a look at Esmeralda Ribeiro's Malungos e Milongas, "A vingança de Dona Léia" and "Guarde Segredo", 2008. Coletado em: http://www.lehman.cuny.edu/ciberletras/v01 n02/Duke.htm.

EVARISTO, C. Da representação à auto-representação da Mulher Negra na Literatura Brasileira. Revista Palmares: cultura afro-brasileira, n.1, ano 1, ago. 2005, p. 52-57.

EVEN-ZOHAR, I. Polysystem Studies: Introduction. Poetics Today, v. 1, n. 1, 1997 [1990]. p. 1-6. Coletado em: http://www.tau.ac.il/ itamarez/works/books/ezpss1990.pdf.

The Position of Translated Literature within the Literary Polysystem. Poetics

Today. v.1, n.1, 1997 [1990]. p. 45-51. Coletado em: http://www.tau.ac.il/ itamarez/works/books/ez-pss1990.pdf.

FEITOSA, Lilian Passos Wichert. Brazilian Women Writers in English: translation of culture and gender in works by Clarice Lispector, Carolina Maria de Jesus, and Ana Maria Machado. 2008. 511p. Dissertation (PhD). Comparative Literature - University of Massachusetts Amherst.

GOMES, M. L. S. D. Identidades Refletidas: um estudo sobre a imagem da literatura brasileira construída por tradução. 2005. 166p. Dissertação (Mestrado em Letras) Departamento de Letras, Pontifícia Universidade Católica do Rio de Janeiro.

JESUS, C.M. Quarto de despejo: diário de uma favelada. 8ed. São Paulo: Editora Ática, 2006.

LEFEVERE, A. Beyond the Process: Literary Translation in Literature and Literary Theory. In: ROSE, Marilyn Gaddis (Ed.). Translation Spectrum: Essays in Theory and Practice. Albany, New York: SUNY Press, 1981. p. 52-59.

. Translation: Its genealogy in the west. In: BASSNETT, Susan \&LEFEVERE, André (Eds.). Translation, History and Culture. London: Pinter Publishers, 1990. p. 14-28.

Tradução, reescrita e manipulação da fama literária. Trad. Claudia Mattos Seligmann. Bauru: Edusc, 2007.

LEVINE, R. The cautionary tale of Carolina Maria de Jesus. Working paper 178, Jun. 1992. Coletado em: https://kellogg.nd.edu/publications/workingpapers /WPS/178.pdf.

LINDOSO, Felipe. A tradução da literatura brasileira. In: Blog Cultura e mercado. 15 de julho de 2011. Disponível em: http://www.culturaemercado.com.br/pontos-devista/a-traducao-da-literatura-brasileira/

MAGNABOSCO, M.; RAVETTI, G. Verbete Carolina Maria de Jesus. In: Catálogo das escritoras brasileiras. Coletado em: http://www.amulhernaliteratura.ufsc.br/ catalogo/carolina_vida.html, criado em 2004. 
MEIHY, J. \& LEVINE, R. Cinderela negra: A saga de Carolina Maria de Jesus. Rio de Janeiro: UFRJ, 1994.

The life and death of Carolina Maria de Jesus. Albuquerque: New Mexico University Press, 1995.

PERPÉTUA, E. A vida escrita de Carolina Maria de Jesus. Rio de Janeiro: Nandyala, 2014.

SANTOS, J. R. Carolina Maria de Jesus: uma escritora improvável. Rio de Janeiro: Garamond, 2009.

SILVA, Fernanda Felisberto. Escrevivências na diáspora: escritoras negras, produção editorial e suas escolhas afetivas uma leitura de Carolina Maria de Jesus, Conceição Evaristo, Maya Angelou e Zora Neale Hurston. 2011. 141p. Tese (Doutorado em Literatura Comparada) - Instituto de Letras, Universidade do Estado do Rio de Janeiro.

SIMON, S. Gender in Translation: Cultural Identity and the Politics of Transmission. London and New York: Routledge, 1996.

SOUZA, Florentina da Silva. Afro-descendências em Cadernos Negros e jornal do MNU. Belo Horizonte: Autêntica, 2005.

VALENTE, M. I. A tradução e a construção de imagens culturais: Ponciá Vicêncio, de Conceição Evaristo, e sua tradução para o inglês. Rio de Janeiro, 2013. 163p. Tese de Doutorado - Departamento de Letras, Pontifícia Universidade Católica do Rio de Janeiro. 